\title{
PESQUISA DE OVOS “PESADOS” DE HELMINTOS NAS FEZES: ESTUDO COMPARATIVO ENTRE OS MÉTODOS DA SEDIMENTAÇÃO ESPONTÂNEA EM ÁGUA E DE RITCHIE
}

\author{
Elaine Guizelini, Vera Lucia Pagliusi Castilho, Antônio Augusto \\ Baillot Moreira, Rubens Campos, Vicente Amato Neto, \\ Eunice José de Sant'Ana, Pedro Luiz Silva Pinto e \\ Clóvis Kiomitsu Takiguti
}

\begin{abstract}
Com a finalidade de melhor conhecer a sensibilidade do método de Ritchie (centrífugo-sedimentação em formol-éter), quanto ao diagnóstico de parasitoses intestinais pelo exame das fezes, foi investigada a capacidade dele no sentido de detectar ovos "pesados" de helmintos (Schistosoma mansoni e Ascaris lumbricoides inférteis). Houve comparação com o desempenho do processo da sedimentação espontânea em água, usado com o mesmo intuito.

Os resultados obtidos e a respectiva avaliação estatística demonstraram que a técnica da sedimentação espontânea em água é mais eficiente, tendo sido analisadas 300 amostras de fezes, metade das quais certamente contendo os dois tipos de ovos citados e a outra parte considerada em trabalho laboratorial rotineiro.
\end{abstract}

Palavras chaves: Parasitoses intestinais. Diagnóstico. Ovos "pesados" de helmintos. Técnicas da sedimentação espontânea em água e de Ritchie.

A expressiva prevalência de parasitoses intestinais no Brasil e em vários outros países gera a necessidade de diagnosticá-las convenientemente e, sobretudo, através de processos laboratoriais ao mesmo tempo eficientes e pouco custosos. Torna-se entāo imperioso, diante dessa circunstância, procurar estipular novos métodos e conhecer devidamente a sensibilidade dos já preconizados.

A técnica de Ritchie, do formol-éter, não é costumeiramente usada em instituições nacionais, merecendo, sem dúvida melhores avaliações. Em análises sobre $o$ assunto ficou evidenciado que ela, calcada em centrifugo-sedimentação, supera a de Faust e col, dependente de centrifugo-flutuação em sulfato de zinco, quando consideradas as demonstrações de cistos de protozoários e de ovos de helmintos; suplementarmente, tem outros atributos, assentados na exigencia de manuseio não muito delicado, na praticabilidade de análise algum tempo após a manipulação preparatória e na aplicação de soluçōes que nāo exigem austera precisão quanto às concentrações ${ }^{2}$. Todavia, com o intuito de melhor definir os atributos pertinentes a tal procedimento, interpretamos como válido verificar se ele é apto a permitir, pelo exame das fezes, satisfatória detecção de ovos "pe-

Trabalho do Laboratório de Investigaçāo Médica Parasitologia, do Hospital das Clínicas, da Faculdade de Medicina da Universidade de São Paulo.

Recebido para publicação em 10/3/86 sados" de helmintos, ou seja, de Schistosoma mansoni e inférteis de Ascaris lumbricoides, que são os comumente importantes, no meio onde exercemos atividades, em trabalhos assistenciais e epidemiológicos. Por isso, o estudo agora relatado foi realizado.

\section{MATERIAL E MÉTODOS}

Compuseram nossa casuística 300 amostras de fezes, encaminhadas à Seção de Parasitologia do Laboratório Central, do Hospital das Clínicas, da Faculdade de Medicina da Universidade de São Paulo. Em 150 (grupo A) estavam presentes ovos de $S$. mansoni e/ou inférteis de $A$. lumbricoides e isso ficou demostrado pela sedimentação espontânea em água, usando o mesmo material; a seguir empreendemos pesquisas pelos processos de Rithie e de Kato-Katz, prestando-se o último citado para determinação quantitativa. Quanto às outras 150 (grupo B), já de início aplicamos os três métodos, sem seleção prévia.

Pelas técnicas em questão, executamos os exames levando em conta as diretrizes apresentadas em compêndio especializado sobre $o$ assunto ${ }^{1}$.

Interpretamos, estatisticamente, os valores propiciados pelo processo da sedimentação espontânea em água como os esperados em face à distribuição considerada; por seu turno, estipulamos os decorrentes do de Ritchie como os observados e recorremos ao teste de Qui-quadrado com o nível de significância de $5 \%{ }^{3}$. 
Guizelini E, Castilho VLP, Moreira AAB, Campos R, Amato Neto V, Sant'Ana EJ, Pinto PLS, Takiguti CK. Pesquisa de ovos "pesados" de helmintos nas fezes: estudo comparativo entre os métodos da sedimentação espontânea em água e de Ritchie. Revista da Sociedade Brasileira de Medicina Tropical 20: 23-24, Jan-Mar, 1987.

\section{RESULTADOS}

Nossas verificaçōes, derivadas da sedimentação em água, estão adiante registradas. Grupo A: positividade para ovos de $S$. mansoni, 89; para ovos inférteis de $A$. lumbricoides, 73; para ovos de $S$. mansoni e infërteis de $A$. lumbricoides concomitantemente, 12 . Grupo B: positividade para ovos de $S$. mansoni, 22; para ovos inférteis de $A$. lumbricoides, 13.

O confronto entre as duas condutas, complementado pelas intensidades de infecção, indicadas pelo procedimento de Kato-Katz, figura nas Tabelas 1 e 2 .

Tabela 1 - Pesquisa aeovos de. Schistosoma mansoninas fezes: comparação entre os métodos da sedimentação espontânea em água e de Ritchie, conforme avaliação quantitativa pelo processo de Kato-Katz.

\begin{tabular}{lcc}
\hline \multirow{2}{*}{\begin{tabular}{c} 
Número de ovos por $\begin{array}{c}\text { Número de exames que revelaram } \\
\text { grama de fezes } \\
\text { Kato-Katz }\end{array}$ \\
\cline { 2 - 3 }
\end{tabular}} & $\begin{array}{c}\text { a presença de ovos } \\
\text { Sedimentação es- } \\
\text { pontânea em água }\end{array}$ & Ritchie \\
\hline Até 100 & 30 & 18 \\
De 100 a 300 & 33 & 18 \\
Mais do que 300 & 48 & 39 \\
\hline
\end{tabular}

Tabela 2 - Pesquisa de ovos inférteis de Ascaris lumbricoides nas fezes: comparação entre os métodos da sedimentação espontânea em água e de Ritchie, conforme avaliação quantitativa pelo processo de Kato-Katz.

\begin{tabular}{lcc}
\hline $\begin{array}{c}\text { Número de ovos por } \\
\text { grama de fezes } \\
\text { Kato-Katz }\end{array}$ & $\begin{array}{c}\text { Números de exames que revelaram } \\
\text { a presença de ovos }\end{array}$ \\
\cline { 2 - 3 } & $\begin{array}{c}\text { Sedimentação es- } \\
\text { pontânea em água }\end{array}$ & Ritchie \\
& & \\
\hline Até 100 & 15 & 6 \\
De 100 a 300 & 14 & 9 \\
Mais do que 300 & 57 & 46 \\
\hline
\end{tabular}

O método de Ritchie nunca mostrou isoladamente os ovos "pesados" e as cifras a ele atinentes diferiram das esperadas, se considerados o da sedimentação espontânea em água como parâmetro e o nivel proposto (ovos de $S$. mansoni: $\mathrm{x}^{2}=13,31$ g.l. $=2 \mathrm{p}<0,05$; ovos inférteis de $A$. lumbricoides: $\mathrm{x}=9,3$ g.l. $=2 \mathrm{p}<0,05$ ).

\section{DISCUSSÃO}

De acordo com o exposto, tornou-se patente que a técnica de Ritchie não possui adequada sensibilidade para mostrar a presença de ovos "pesados" nas fezes, sendo essa circunstância ponderável se levarmos em conta que, no Brasil, esquistossomose mansonica e ascaridíase constituem verminoses comuns. Tal fato ficou bem evidenciado através da metodologia que escolhemos e pela apreciação estatística.

A deficiência em tela esteve demarcada, no que tange às duas helmintíases, quando acentuadas ou não, quantitativamente; não obstante, apareceu de maneira mais clara em face a pequenos números de ovos.

Nossa investigação, de caráter eminentemente prático, conduz à dedução de que o processo de Ritchie tem méritos limitados se pretendidos diagnósticos razoavelmente seguros ou inquéritos epidemiológicos confiáveis, estando em foco as parasitoses atribuiveis ao $S$. mansoni e ao $A$. lumbricoides.

\section{SUMMARY}

The sensitivity of Ritchie's technique (centrifugal sedimentation in formol-ether) in the diagnosis of intestinal parasitic diseases was investigated, regarding the detection of heavy helminth eggs (Schistosoma mansoni and infertile Ascaris lumbricoides eggs) in stool specimens. Its performance was compared to that obtained with the technique of spontaneous sedimentation in water.

Statistical evaluation of the results in 300 stool specimens yields a higher efficacy with the technique of spontaneous sedimentation in water. Half of the stool specimens examined were known to contain both above-mentioned eggs and the others were part of the laboratory routine.

Key words: Intestinal parasitic diseases. Diagnosis. Heavy helminth eggs. Ritchie's and spontaneous sedimentation in water techniques.

\section{REFERÊNCIAS BIBLIOGRÁFICAS}

1. Amato Neto V, Corrêa LL. Exame parasitológico das fezes. Sarvier, São Paulo, 1980.

2. Castilho, VPV, França IL, Monteiro CJA, Amato Neto V, Campos R, Moreira AAB. Estudo comparativo entre os métodos de Faust \& col. e de Ritchie, para exame parasitológico das fezes. Revista do Instituto de Medicina Tropical de São Paulo 22:319-322, 1980.

3. Gomes FP. Curso de estatística experimental. 10a edição, Livraria Nobel SA, São Paulo, 1982. 